\title{
Sustainable Green SLA (GSLA) Validation using Bayesian Network Model
}

\author{
Iqbal Ahmed \\ Graduate School of Science and Engineering \\ Saga University, Saga, Japan \\ Hiroshi Okumura \\ Graduate School of Science and Engineering \\ Saga University, Japan
}

\author{
Kohei Arai \\ Graduate School of Science and Engineering \\ Saga University, Japan \\ Osamu Fukuda \\ Graduate School of Science and Engineering \\ Saga University, Japan
}

\begin{abstract}
Currently, most of the IT (Information Technology) and ICT (Information and Communication Technology) industries/companies provides their various services/product at a different level of customers/users through newly developed sustainable GSLA (Green Service Level Agreement). In addition, all these industries also designed new green services at their scope by using global sustainable GSLA informational model. The recent development of sustainable GSLA under 3Es (Ecology, Economy and Ethics) are assisting these IT and ICT based industries to practice sustainability by providing green services to their customers/users and thus respecting green computing paradigm. However, the evaluation of newly developed sustainable GSLA model is not validating yet. This research attempts to evaluate and validate the sustainable GSLA model by using Bayesian Network Model (BNM). The validation of using BNM is done with the feedback of 44 different IT and ICT based companies from Japan, India and Bangladesh. The average accuracy of using BNM for validating sustainable GSLA model is $68 \%$ while considering all sample data sets. Moreover, while the proposed BNM have higher confidence with entropy calculation, then the accuracy is almost $100 \%$ for most of the companies' feedback. The proposed idea of using BNM for evaluating and validating sustainable GSLA model would definitely help the ICT engineer to design and develop future green services in their industries. Additionally, the evaluation also validates the proposed information sustainable GSLA model from previous research.
\end{abstract}

Keywords-GSLA; Sustainability; GSLA informational model; Bayesian Network

\section{INTRODUCTION}

Green SLA(GSLA) is a formal agreement between service providers/vendors and users/customers incorporating all traditional/basic commitments (Basic SLAs) [1] as well as incorporating Ecological, Economical, and Ethical (3Es) aspects of sustainability [2]. The growth rate of SLA in recent time is increasing as well as the need of sustainable GSLA for achieving sustainability in IT industry [3]. However, the IT and ICT sectors mostly concern about energy or power consumption, recycling and productivity issues under green computing domain whereas practicing a viable sustainable GSLA is still far away from reality in the industry. Therefore, the introduction of sustainable GSLA informational model [4], helps ICT engineer to find out all missing green parameters and their management complexity by covering three pillars (3Es) of sustainability. This research reveals the inclusion of using Bayesian Network Model (BNM) for validating the sustainable GSLA model and thereby, assisting ICT engineer to practice real sustainability in their product/service deployment. The proposed BNM includes 09 green parameters from ecological pillars, 04 parameters from economic pillars, 07 parameters from ethical pillars and product life cycle of sustainable GSLA informational model [2, 3, 4].

The following section introduces research background followed by proposed BNM for evaluating and validating sustainable GSLA model. Then the analytical results and discussion are followed by some conclusion and future work plans.

\section{RESEARCH BACKGROUND}

The validation and proper design of sustainable GSLA model allow IT and ICT industries to practice sustainability in their scope under 3Es. Figure 1 below shows how sustainability is related to ecological, economical and ethical parameters. The trade-off between these 3Es could define sustainability.

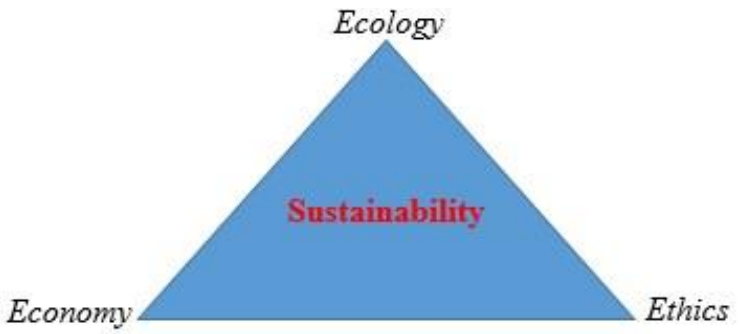

Fig. 1. 3Es of Sustainability Achievement

Presently, the revolution of ICTs and IT in daily average life has also resulted in the increase of Green House Gas(GHG), due to a continual increase in global "carbon footprint" [5]. In, 2007, the ICT sector produced as much as GHG as the aero industry and is projected to grow rapidly [5, 6]. Therefore, it is now timely to introduce more sustainable product/services, green IT services (Gartner 2015) for the future world [7]. Indeed, the dimensions of green informatics and green computing contributions are going on by many 
researchers [8]. On the other side, to understand the contribution of green computing and green informatics, it is worth to develop a new sustainable GSLA for the customers/users. There were many empirical works been done on GSLA. S. Klingert et al. [9] introduced the concept of GSLAs and their work focused on identifying hardware and software techniques for reducing energy consumption, integrating green energy. Z.S. Andreopoulou [8] proposed a model, - ICT for Green and Sustainability whereas SMART 2020 report [6] gives the idea of GHG emission from the ICT sector. G.V. Laszewski et al. [10] invented a framework towards the inclusion of Green IT metrics for grid and cloud computing. Md. E. Haque et al. [11] and [12] offer a new class of green services in response to practice sustainability in the IT field. R. R. Harmon et al. and others [12, 13, 14, 15, 16, $17,18]$ discovered that sustainable IT services require the integration of green computing practice such as power management, virtualization, cooling technology, recycling, electronic waste disposal and optimization of IT infrastructure. In $[19,20,21]$, the authors discussed the most significant aspects of sustainable GSLA, -IT ethics issues. Their main research is to develop the ethics program in the ICT industry. Most of these existing GSLA work is mainly based on the green service information, their operations, metrics information, theoretical framework development and IT ethics issues for grid and cloud computing industry. The details analytical basic SLAs and existing green SLA (GSLA) work have been done by [3]. Additionally, sustainable GSLA informational model has been developed based on all missing parameters of three pillars of sustainability (3Es) by [3, 4]. The new green IT services have been designed based on the information model [2, 4] too. However, there is no work/research have been done on the evaluation or validation of sustainable GSLA model until now.

This research includes all parameters of sustainable GSLA model using the Bayesian network and thereby, analysis the output of BNM and validate the informational model for IT and ICT industries. The BNM takes into the consideration of 50 different IT and ICT based companies' feedback from Japan, India and Bangladesh. The findings of BNM would definitely assist the ICT engineer to develop a viable sustainable GSLA for their company in future. The analytical accuracy of BNM also helps us to validate the proposed sustainable GSLA information model [4]. The findings of practicing sustainability around these 50 different companies are also analysed with JMP analytical tool by SAS Corporation, USA. The main aim of using BNM for sustainability achievement by using questionnaires from all these companies was completely unbiased. The next section will introduce the details of BNM for validating sustainability model and then followed by analytical results and discussion.

\section{VALIDATION OF SUSTAINABLE GSLA MODEL USING BAYESIAN NETWORK}

Create a BNM to evaluate/implement the general global informational model of sustainable GSLA parameters in different industries in the society, which varies according to industry size and business type. BNM model helps to evaluate the proposed GSLA model with high confidence. Moreover, Bayesian network model helped to visualize the changes of posterior probability as the evidence/sample increases and thus assists to improve the accurate evaluation of GSLA with other methods. Figure 2 shows the proposed BNM tree structure for validating sustainable GSLA model.

The model takes into account 09 parameters under ecological pillars, 04 parameters from economic pillars and 07 parameters from ethical parameters to achieve sustainability. In total, 50 different industries are taken into consideration in this evaluation according to 20 parameters under 3Es. It is evident from their data that, still all of these industries are far away from the establishment of sustainable GSLA in their scope. However, all this prior information could be used in the designed BNM to get posterior information. Therefore, the BNM model actually shows the accurate importance of parameters to work out for achieving sustainability.

Table 1 represents all the parameters under three pillars of sustainability (3Es) in the proposed tree structure of the Bayesian network (Figure 2).

TABLE I. All PARAMETERS FOR DESIGNING BAYESIAN NETWORK MODEL

\begin{tabular}{|l|l|l|}
\hline \multicolumn{1}{|c|}{ Ecological } & \multicolumn{1}{|c|}{ Economic } & \multicolumn{1}{c|}{ Ethical } \\
\hline P1-Recycling & P1-Energy Cost & P1-Satisfaction level \\
P2-eWastage & P2-Carbon Taxation & P2-Gender Balance \\
P3-Energy Consumption & P3-Cooling Cost & P3-Salary Balance \\
P4-Carbon Emission & P4-Civil Engineering & P4-Product Security \\
P5-Earth Pollution & Cost & P5-Product reliability \\
P6-Comfort Pollution & & P6-Patent/IPR \\
P7-Obsolescence & & P7-Product Performance \\
Indication & & \\
P8-Radio Wave & & \\
Information & & \\
P9-Toxic Material & & \\
Information & & \\
\hline
\end{tabular}

A. Flow graph of using Bayesian Network Model (BNM) for sustainable GSLA:

Figure 3 represents the stepwise GSLA model evaluation using BNM with the help of Bayonet 6 software Tool, developed by AIST, Tosu, Japan. The output of the BNM is also analysed using JMP software, developed by SAS cooperation, USA. 


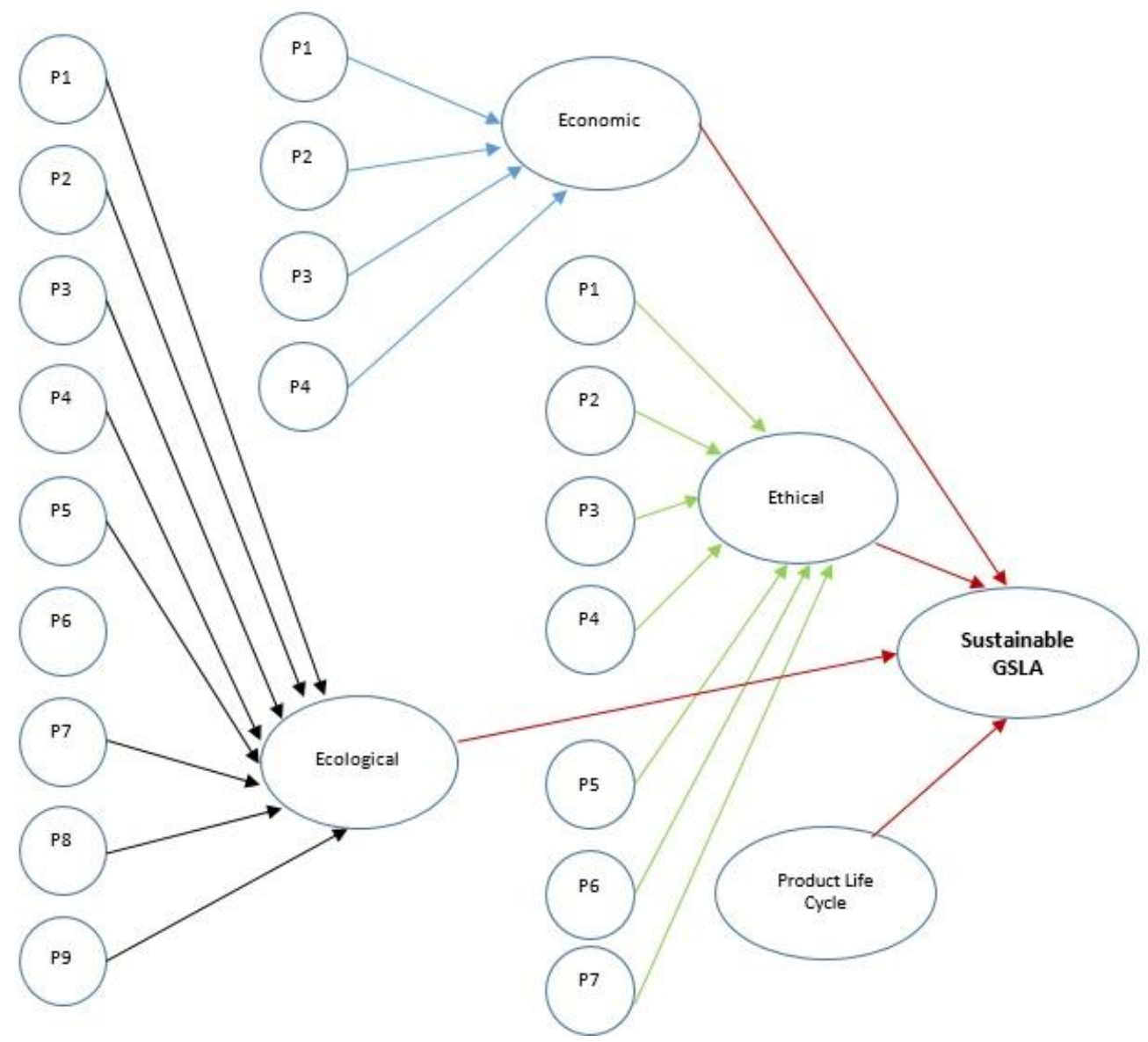

Fig. 2. The proposed Bayesian network tree structure for sustainable GSLA model
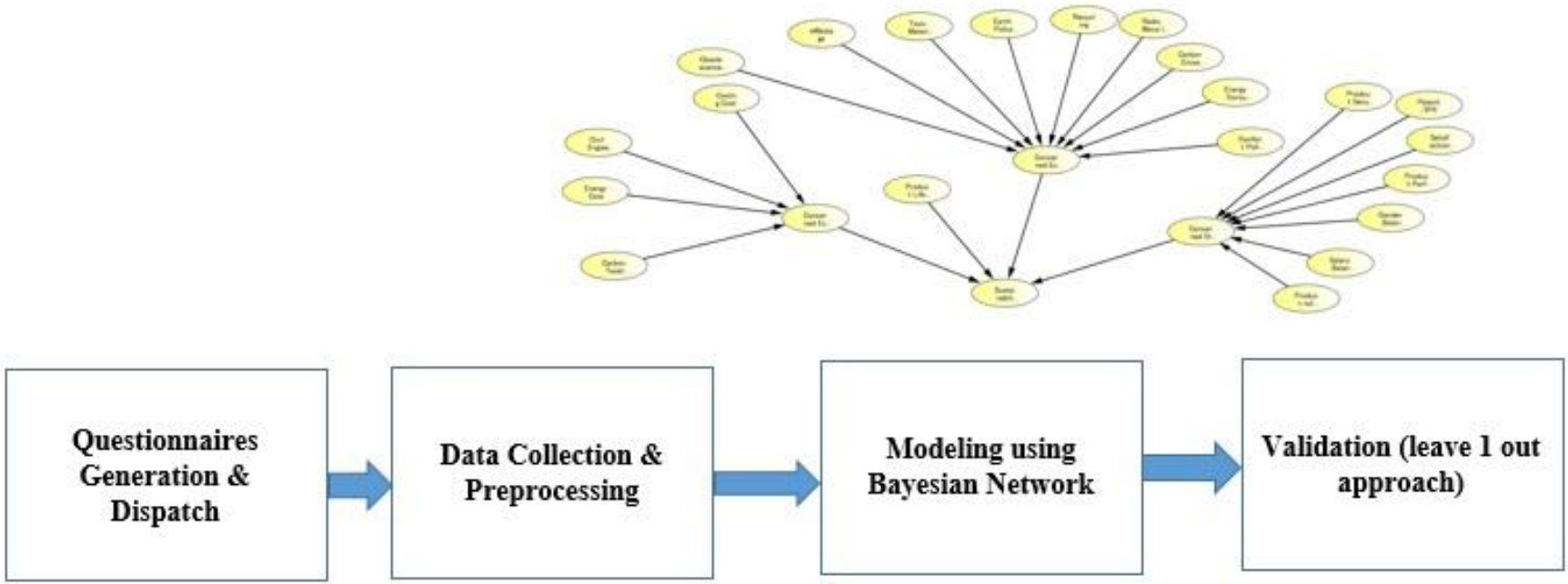

Fig. 3. The overall evaluation method using BNM

1) Questionnaires Generation and Dispatch:

The proposed sustainable GSLA informational model [4] is usually designed theoretically through rigorous literature review and their analysis. The evaluation of this informational model could be done by designing questionnaires regarding that model. Therefore, initially questionnaires created and then dispatched these questions to various IT and ICT industries in
Japan and around other countries. In total, 55 questions asked under three pillars (Ecology, Economy and Ethics). The feedback of all these questions are collected in hard copy format from 50 various industries in Japan, India and Bangladesh. Most of these industries are chosen in the field of ICT and varies in different sizes (small, medium and large size companies). 
2) Data Collection and Pre-processing:

The feedbacks of all questionnaires are collected in regular Microsoft-Excel program and processed for using Bayonet Tool as the tool accept only .csv format files. In total, 44 industries return back their feedbacks regarding the sustainability practice in the scope of GSLA according to our questionnaires. All these feedbacks are completely unbiased and were asked to the responsible person of the companies, though most of these companies still have a lack of green expert CEO or management in some perspectives.
3) Modelling using Bayonet Tool:

The feedback from various industries is then analysed using Bayesian Network Model (BNM). The learning of BNM includes 44 individual data and rest 1 data used for test purpose. The 1 leave out approach improves the accuracy of the model and therefore 44 individual sets of learning and testing data sets used to validate the proposed Bayesian structure. The learning is based on Greedy search algorithm and the information criteria AIC is used by Bayonet 6 software tool (Figure 4).

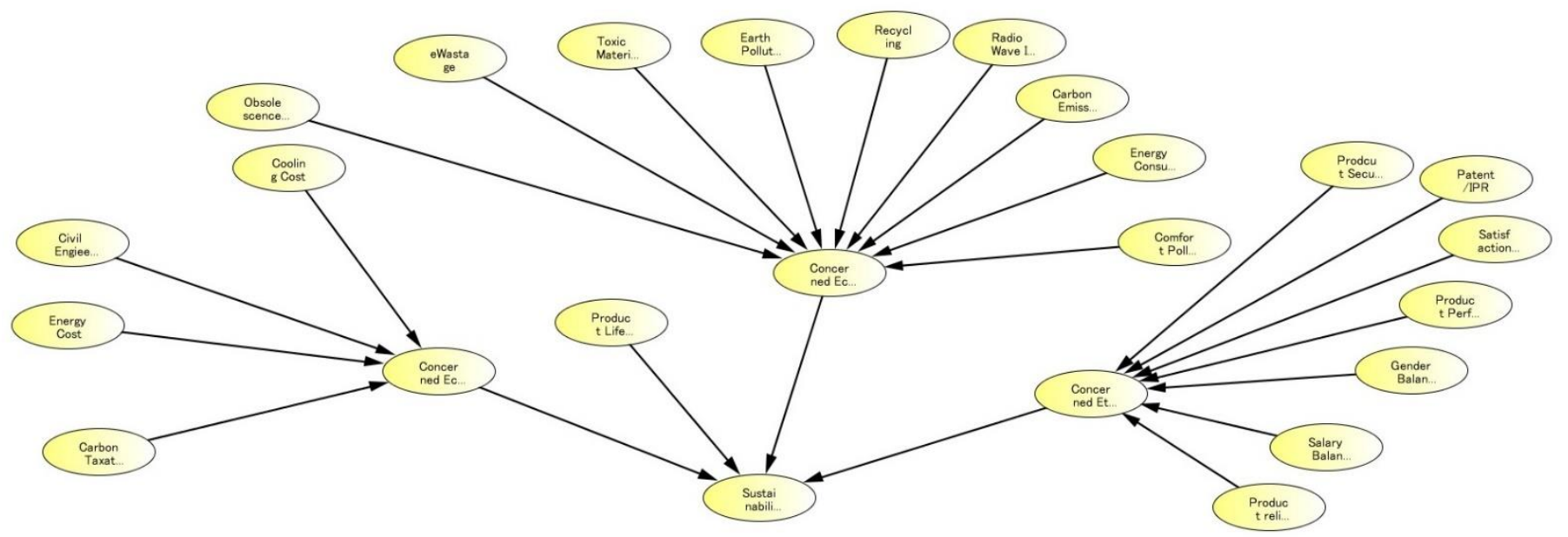

Fig. 4. Screen shots of Bayonet 6 Software Tool

\section{RESULTS AND DISCUSSIONS}

The feedback of all 44 companies analysed to validate sustainable GSLA model using JMP analytical tool (SAS Corporation, USA) and Bayonet Tool (AIST, Japan). Among the 50 companies, 06 companies feedback could not be accepted due to the lack of proper information according to designed questionnaires. In general, most of the industries concerned about three pillars of sustainability (Ecology,

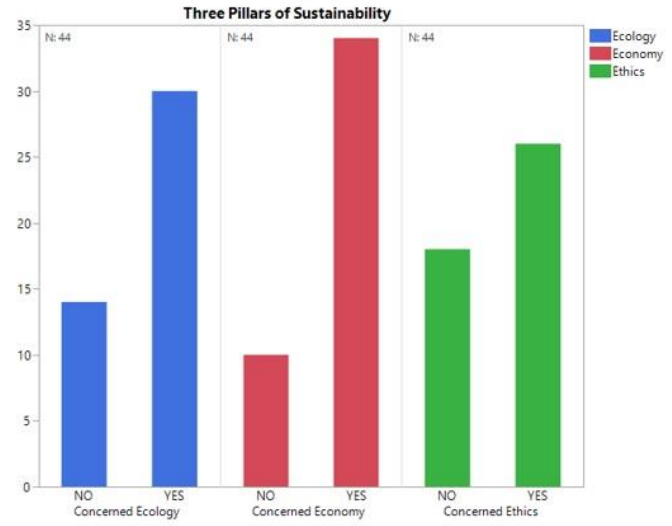

Economy and Ethics). According to the next distribution figure, almost 23 companies concerned about sustainability practice. However, the next Figure 5 also demonstrates that most of these companies are mainly concerned with ecology and economy than their ethical point of view. Interestingly, most companies are mainly concerned about the economic aspects (profit) in their scope. Later, the research reveals some other interesting facts about all three sustainability pillars.

Fig. 5. Distribution of Sustainability practice and their main three pillars according to all companies

Figure 6 illustrates that among the 09 parameters for ecological aspects of GSLA, the most ignored 03 parameters are: Obsolescence Indication (P7), Radio Wave Information (P8) and Toxic Material Information (P9) [4]. Most of the ICT based companies are ignoring these 03 parameters of GSLA model, whereas they are pretending to concerned about ecology for sustainability practice in their product or service development. 


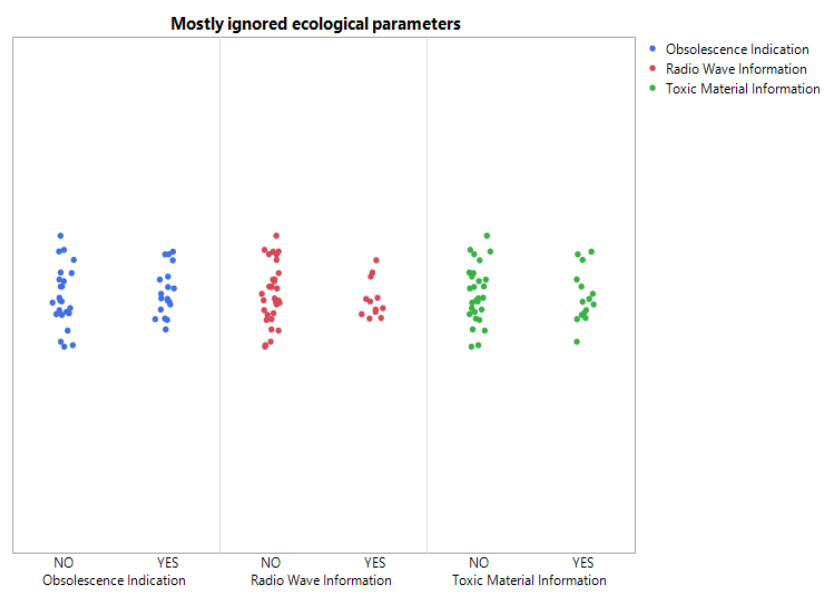

Fig. 6. The mostly ignored ecological parameters from the companies

Figure 7 shows the average concerned three pillars of sustainability for all companies' feedback. The concerned ecology is almost $68 \%$, the economy is $72 \%$ and ethical concern is $61 \%$ for achieving sustainable GSLA model in their current product or service deployment.

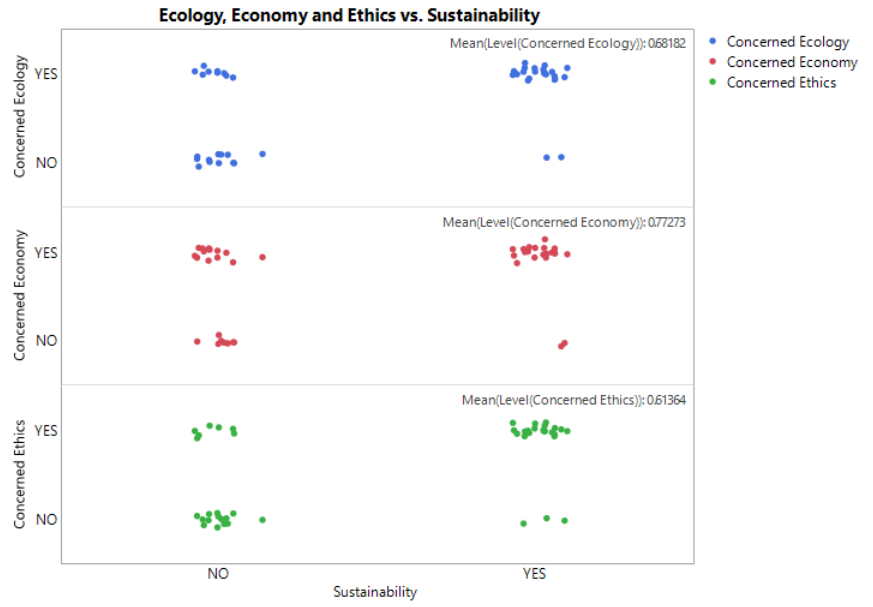

Fig. 7. Averagely concerned ecology, economy and ethics vs. Sustainability

In the economic aspects of sustainability, the most interesting point is that, very few companies are currently concerned about carbon taxation (P2) [4], though most of the companies showed that they are very much concerned about the economic parameters of sustainability but they did not focus on the carbon tax (Figure 8). This is due to lack of proper authority/law or governess according to their country's perspective.

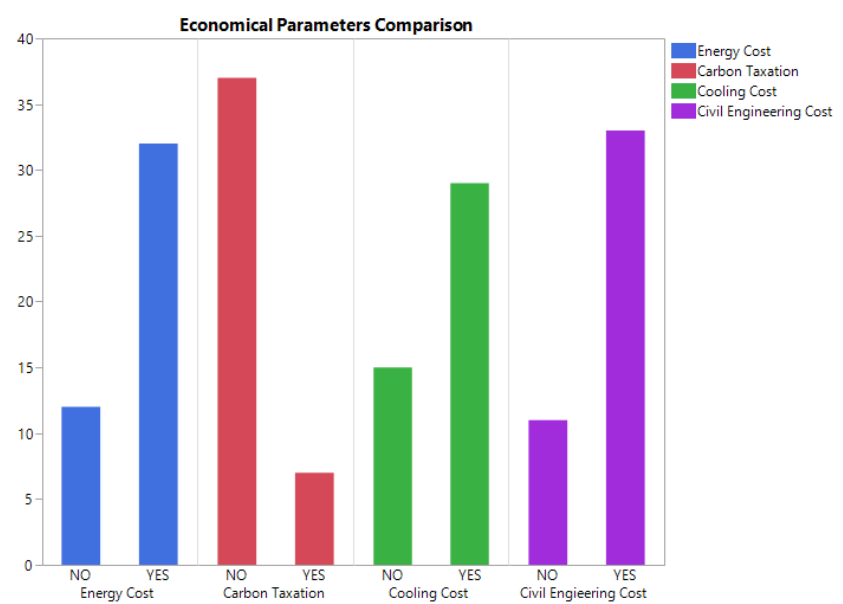

Fig. 8. Comparison between economic parameters of sustainable GSLA

ICT product life cycle is another main aspect in the proposed designed GSLA informational model [3, 4] and considers the BNM structure as an individual parameter (Figure 2). The feedback regarding ICT product life cycle and sustainability in the next figure demonstrates its importance and validates the model to some extent (Figure 9a). According to different companies' feedback, most of the companies consider their product/service reliability and security as the product/service performance (Figure 9b). While considering the product performance, these industries misunderstood ICT product life cycle in their scope too [3]. Only $34 \%$ of the ICT based industries considering Product Life Cycle, while practicing sustainability in their service/product deployment.

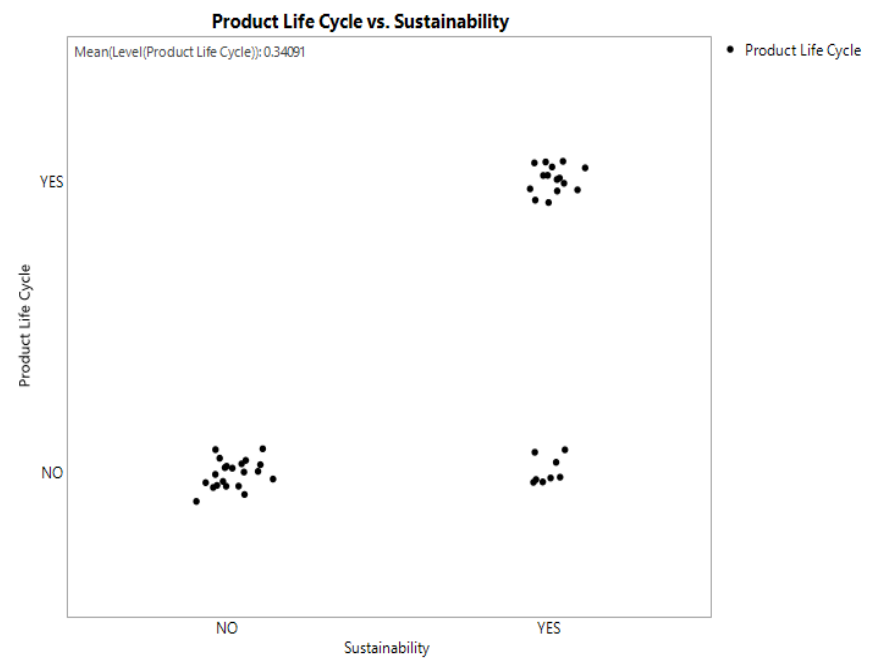

(a). 


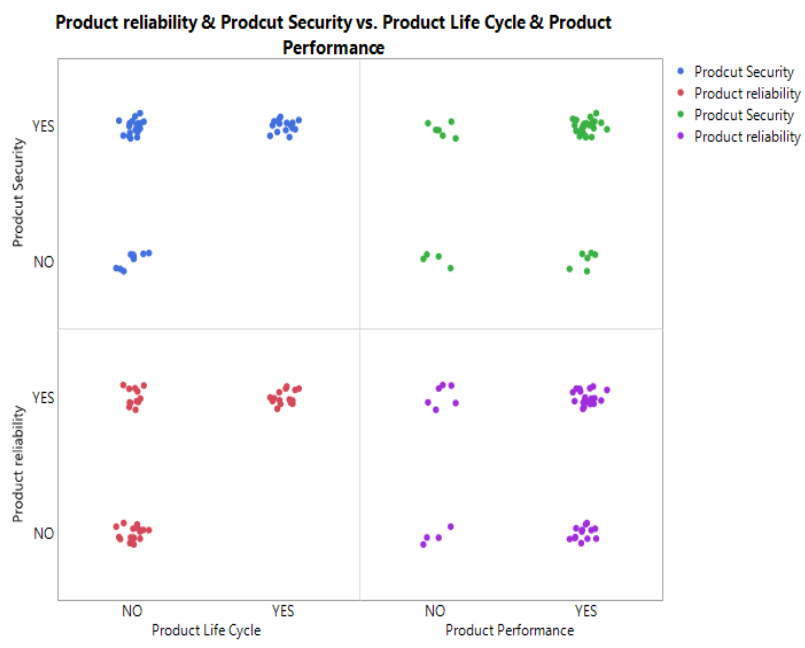

(b).

Fig. 9. (a). Product Life cycle vs. sustainability (b). Comparison between Product life cycle vs their performance in accordance with product reliability and security

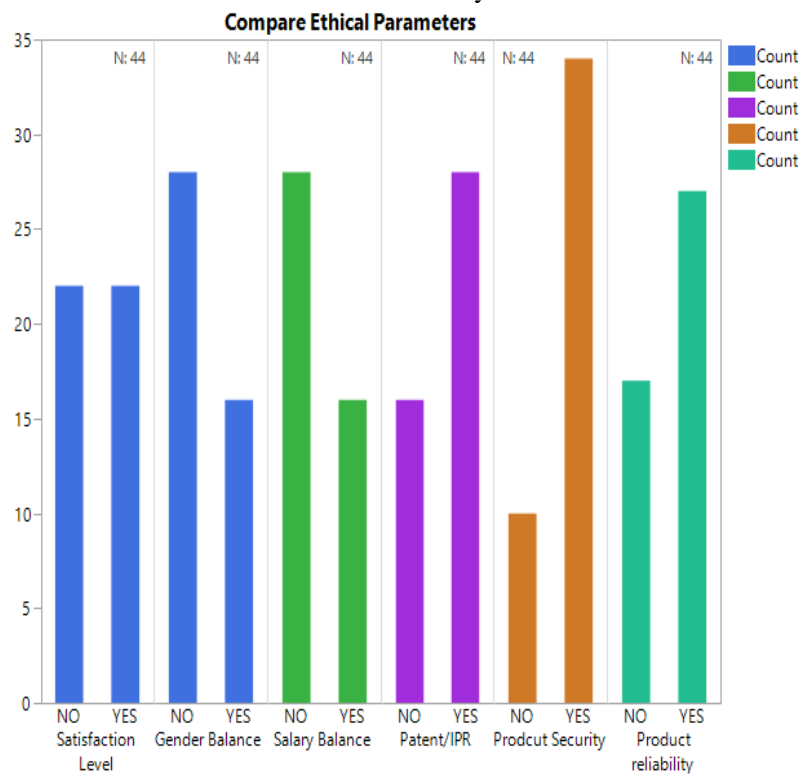

Fig. 10. Comparison between ethical parameters of sustainable GSLA

Figure 10 compared the most significant ethical pillars of sustainable GSLA model [3]. The user satisfaction $(P 1)$, gender $(P 2)$ and salary balance information $(P 3)[4]$ are mostly ignored and companies did not respect these parameters whereas they are mostly concern about IPR/Patent(P6), product reliability $(P 7)$ and security information $(P 4)$ [4]. The most interesting facts show the distribution that almost 27 companies argue that they are concerned about ethics but not considering all important ethical parameters of proposed GSLA model. The above distribution shows the fact here.

\section{A. Bayesian Network Model (BNM) result analysis:}

BNM finally helps to evaluate the general global informational sustainable GSLA model by analysing all feedback from different ICT based companies. This model helps to visualize the proposed GSLA model with higher confidence. Moreover, the validation of the model is done by leaving 1 data set out approach; therefore, in total 44 test data sample sets are created. All these test samples helped to visualize the posterior probability as the number of evidence/sample increases in future. The average accuracy of proposed BNM for sustainable GSLA model is almost 68\% while considering all 44 test data sets. When the average loglikelihood is $<0.5$ the accuracy is almost $100 \%$ for $28(16+12)$ test samples. However, when the likelihood is $>1.5$, the estimation accuracy is very low for only 03 test samples. Figure 11 illustrates the average accuracy of proposed BNM with average log-likelihood.

In addition, the research discovered that, the test sample data might not be enough to justify the proposed Bayesian model. Therefore, the entropy of proposed BNM model's outputs was calculated to achieve reliable discrimination and use it for discrimination-suspension rule [22, 23]. Entropy means or interprets as the risk of incorrect discrimination and if entropy exceeds some predefined discrimination threshold, then the discrimination could be suspended. The following equation used to calculate the entropy between two states of sustainability achievement in the designed model.

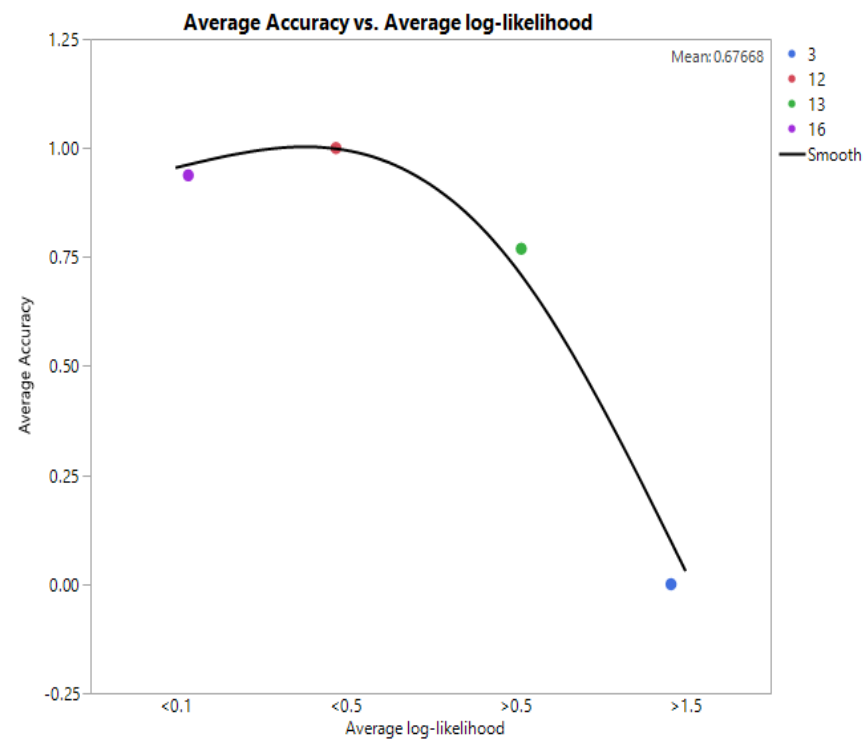

Fig. 11. The proposed BNM average accuracy for evaluating sustainable GSLA model

entropy $=-\sum_{i}^{n} P_{i} \log P_{i}$

where, $P_{i}=$ results of posterior probability for the Sustainability achievement (yes/1) or not (no/0). The higher entropy value means the designed network model is ambiguous and less entropy indicates the more confident model. According to the next Figure 12, while the model has higher confidence (less entropy value <0.18), it is $100 \%$ accurate for 15 company's data sets. Additionally, when the entropy value is $<0.23$, the accuracy of the model is lies within $75-80 \%$ for 16 other company's data sets. Therefore, the overall validation of our proposed sustainable GSLA model could be achieved almost $100 \%$ accurately according to discrimination-suspension rule for proposed BNM. 


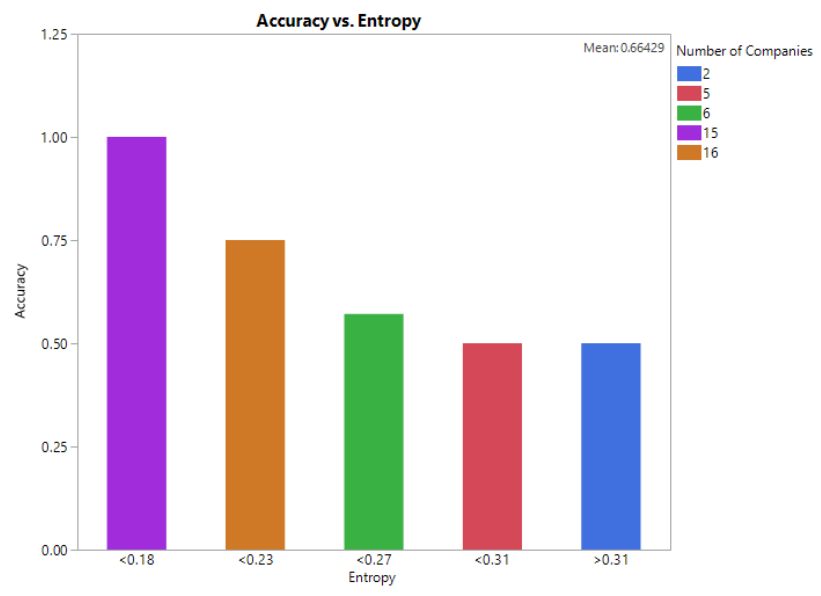

Fig. 12. The accuracy of proposed BNM with higher confidence

\section{CONCLUSION AND FUTURE WORKS}

GSLA research did questionnaires generation and their feedback analysis by using Bayesian Network Model (BNM) for IT and ICT based industries in Japan, India and Bangladesh. The analysis is mainly carried out to validate the sustainable GSLA informational model to achieve sustainability in product/service design/deployment. The validation of sustainable GSLA model is done by using 44 company's feedback analysis and the average accuracy for using BNM is almost $68 \%$. The BNM model with the higher confidence shown $100 \%$ accurate estimation of sustainability practice for 15 companies and more than $75 \%$ for 16 other companies.

The validation of sustainable GSLA model would definitely boost up the current IT and ICT based industry to develop new sustainable GSLA for their services. Moreover, the analysis and validation results also assist the ICT engineer in incorporating the missing parameters for sustainability under 3Es (Ecology, Economy and Ethics). However, the research still believes that incorporating or managing all parameters under 3Es of sustainability is a challenging task. Designing a sustainable GSLA with subjective, qualitative parameters with ethical issues need proper standardization and or laws and directives according to different countries. Additionally, it is worth to mention here that, the definition of sustainable GSLA is still in its early stages and need proper Green ICT solutions and Green expert for realization in the industry. The standardization of green parameters is one of the main issues as mentioned by ITU-T report (2012). The research believes that, the validation of proposed sustainable GSLA model using BNM provides a new dimension in this arena and helps to define future strategy in the business world. In future, the author would like to work on standardization of few green, ethical parameters and their monitoring aspects for the IT and ICT based industry.

\section{ACKNOWLEDGMENT}

The author would like to thank all the companies/industries in Japan, India and Bangladesh, which helped to provide their feedbacks for this research. The authors also show their gratitude to Mr. Bando and Mr.
Hamano for helping questionnaires dispatching and collecting from Japanese companies.

\section{REFERENCES}

[1] L. Wu, and R. Buyya, "Service Level Agreement (SLA) in Utility Computing Systems," Performance and Dependability in Service Computing: Concepts, Techniques and Research Directions, V. Cardellini et. al. (eds), ISBN: 978-1-60-960794-4, IGI Global, Hershey, PA, USA, July 2011, pp.1-25.

[2] I. Ahmed, H. Okumura, and K. Arai "Identifying Green Services using GSLA model for Achieving Sustainability in Industries," International Journal of Advanced Computer Science and Applications, Vol.7, No.9, September 2016, pp. 160-167.

[3] I. Ahmed, H. Okumura, and K. Arai "Analysis on Existing Basic Slas and Green Slas to Define New Sustainable Green SLA," International Journal of Advanced Computer Science and Applications, Vol.6, No.12, December 2015, pp. 100-108.

[4] I. Ahmed, H. Okumura, and K. Arai "An Informational Model as a Guideline to Design Sustainable Green SLA (GSLA)," International Journal of Advanced Computer Science and Applications, Vol.7, No.4, April 2016, pp. 302-310.

[5] J. Mankoff, R. Kravets, and E. Blevis, "Some Computer Science Issues in Creating a Sustainable World," Computer, Vol. 41, No. 8, 2008.

[6] SMART 2020 Report, "Enabling the low carbon economy in the information age," The Climate Group, GeSI, 2008.

[7] Gartner Report (2015), Source: http://www.gartner.com/it-glossary/itservices.

[8] Z. S. Andreopoulou, "Green Informatics: ICT for Green and Sustainability," Journal of Agriculture Informatics (EIFTA), Vol. 3, No. 2, 2012.

[9] S. Klingert, T. Schulze, and C. Bunse, "GreenSLAs for the energyefficient management of data centres," International Conference on Energy-Efficient Computing and Networking, May, 2011.

[10] G. von Laszewski, and L. Wang, "GreenIT Service Level Agreements," Grids and Service-Oriented Architectures for Service Level Agreements, Springer Science, LLC, 2010, pp. 78-88.

[11] Md. E. Haque, K. Le, I. Goiri, R. Bianchini, and T. D. Nguyen, "Providing Green SLAs in High Performance Computing Clouds," International Green Computing Conference, June, 2013.

[12] R. R. Harmon and N. Auseklis, "Sustainable IT Services: Assessing the Impact of Green Computing Practices," IEEE xplore, Proceeding of Portland International Centre for Management of Engineering and Technology, PICMET, August, 2009.

[13] A. P. Bianzino, C. Chaudet, D. Rossi, and J. Rougier, "A Survey of Green Networking Research," IEEE Communication Surveys and Tutorials, Vol. 14, Issue. 1, December 2010, pp. 3-20.

[14] A. Amokrane, M. F.Zhani, Qi Zhang, R. Langar, R. Boutaba, and G. Pujolle, "On Satisfying Green SLAs in Distributed Clouds" $10^{\text {th }}$ International Conference on Network and Service Management (CNSM), November 2014, pp. 64-72.

[15] A. Atrey, N. Jain, and Iyengar N. Ch. S. N, "A Study on Green Cloud Computing," International Journal of Grid and Distributed Computing, Vol. 6, No. 6, 2013, pp. 93-102.

[16] A. C. Orgerie, "A Survey on Techniques for Improving the Energy Efficiency of Large Scale Distributed Systems," ACM Computing Surveys (CSUR), Vol. 46, Issue 4, April 2014.

[17] E. Rondeau, F. Lepage, J. P. Georges, and G. Morel, "Measurements and Sustainability," Chapter 3, Green Information Technology, 1st Edition, A Sustainable Approach, Dastbaz \& Pattinson \& Akhgar, ISBN: 9780128013793, Elsevier Book, 304 pages, March 2015.

[18] C. Li, A. Qouneh, and T. Li, "iSwitch: Coordinating and Optimizing Renewable Energy Powered Server Clusters," International Symposium on Computer Architecture, May 2011.

[19] F. H. Grupe, T. Gracia-Jay, and W. Kuechler, "Is It Time For An IT Ethics Program?," Information Management: Strategy, Systems and technologies, Aurerbach Publications, CRC Press LLC, 2002. 
[20] R. Herold, Introduction to Computer Ethics, Source: http://www.infosectoday.com/Articles/Intro_Computer_Ethics.htm , Retrieved on March 2015.

[21] W. Maner, "Unique Ethical Problems in Information Technology," Journal of Science and Engineering Ethics, Vol. 2, No. 2, April 1996, pp. 137-154.

[22] O. Fukuda, T. Tsuji, and M. Kaneko, "A human supporting manipulator based on manual control using EMG signal," Journal of the Robotics Society, Japan, Vol. 18, No. 3, 2000, pp.79-86.

[23] I. Ahmed, K. Endo, O. Fukuda, K. Arai, H. Okumura, and K. Yamashita, "Japanese Dairy Cattle Productivity Analysis using Bayesian Network Model (BNM)," International Journal of Advanced Computer Science and Applications, Vol.7, No.11, November 2016, pp. 31-37.

\section{AUTHORS' PROFILE}

Kohei Arai, He received BS, MS and PhD degrees in 1972, 1974 and 1982, respectively. He was with The Institute for Industrial Science and Technology of the University of Tokyo from April 1974 to December 1978 also was with National Space Development Agency of Japan from January, 1979 to March, 1990. During from 1985 to 1987, he was with Canada Centre for Remote Sensing as a Post-Doctoral Fellow at National Science and Engineering Research Council of Canada. He moved to Saga University as a Professor in Department of Information Science on April 1990. He was a councillor for the Aeronautics and Space related to the Technology Committee of the Ministry of Science and Technology during from 1998 to 2000. He was a councillor of Saga University for 2002 and 2003. He also was an executive councillor for the Remote Sensing Society of Japan for 2003 to 2005. He is an Adjunct Professor at University of Arizona, the USA since 1998. He also is Vice Chairman of the Commission "A" of ICSU/COSPAR since 2008. He wrote 37 books and published 570 journal papers. He is now Editor-in-Chief of IJACSA and IJISA.
Osamu Fukuda received his B.E. degree in mechanical engineering from Kyushu Institute of Technology, lizuka, Japan, in 1993 and the M.E. and Ph.D. degrees in information engineering from Hiroshima University, Japan in 1997 and 2000, respectively. From 1997 to 1999, he was a Research Fellow of the Japan Society for the Promotion of Science. He joined Mechanical Engineering Laboratory, Agency of Industrial Science and Technology, Ministry of International Trade and Industry, Japan, in 2000. Then, he was a member of National Institute of Advanced Industrial Science and Technology, Japan from 2001 to 2013. Since 2014, he has been a Professor of Graduate School of Science and Engineering at Saga University, Japan. Prof. Fukuda won the K. S. Fu Memorial Best Transactions Paper Award of the IEEE Robotics and Automation Society in 2003. His main research interests are in human interface and neural networks. Also, he is currently a guest researcher at National Institute of Advanced Industrial Science and Technology, Japan. Prof. Fukuda is a member of IEEE and the Society of Instrument and Control Engineers in Japan.

Iqbal Ahmed got his Bachelor of Science (BSc) Honours degree in Computer Science and Engineering from University of Chittagong, Bangladesh in 2007 and achieved a joint Master degree from PERCCOM program of European Union in September 2015. He received his Master of Complex System Engineering degree from University of Lorraine (UL), France then Master in Technology from Lappeenranta University of Technology (LUT), Finland and Master degree in Pervasive Computing and Communication for Sustainable development from Lulea University of Technology (LTU), Sweden. Since October 2015, he is enrolled as a doctoral student in the Department of Information Science, Saga University, Japan. In the profession, he worked in the Department of Computer Science and Engineering, University of Chittagong, Bangladesh as an Assistant professor since February 2011. He has been awarded Cat-A scholarship of Erasmus Mundus from the European Union two times in 2010 and 2013 respectively. His current research interest lies in the field of green and sustainable computing and information processing. 